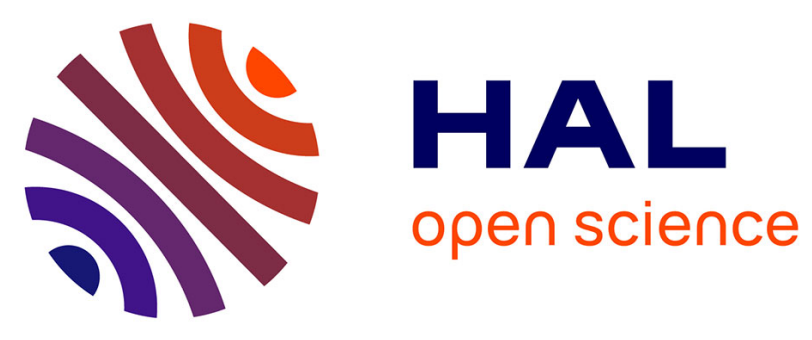

\title{
Deleterious 1100delC and L303X mutants identified among 38 human breast cancer cell lines
}

Marijke Wasielewski, Pejman Hanifi-Moghaddam, Antoinette Hollestelle, Sofia D. Merajver, Ans Ouweland, Jan G. M. Klijn, Stephen P. Ethier, Mieke Schutte

\section{To cite this version:}

Marijke Wasielewski, Pejman Hanifi-Moghaddam, Antoinette Hollestelle, Sofia D. Merajver, Ans Ouweland, et al.. Deleterious 1100delC and L303X mutants identified among 38 human breast cancer cell lines. Breast Cancer Research and Treatment, 2008, 113 (2), pp.285-291. 10.1007/s10549-0089942-3 . hal-00478318

\section{HAL Id: hal-00478318 https://hal.science/hal-00478318}

Submitted on 30 Apr 2010

HAL is a multi-disciplinary open access archive for the deposit and dissemination of scientific research documents, whether they are published or not. The documents may come from teaching and research institutions in France or abroad, or from public or private research centers.
L'archive ouverte pluridisciplinaire HAL, est destinée au dépôt et à la diffusion de documents scientifiques de niveau recherche, publiés ou non, émanant des établissements d'enseignement et de recherche français ou étrangers, des laboratoires publics ou privés. 


\title{
Deleterious CHEK2 1100delC and L303X mutants identified among 38 human breast cancer cell lines
}

\author{
Marijke Wasielewski · Pejman Hanifi-Moghaddam • Antoinette Hollestelle • \\ Sofia D. Merajver · Ans van den Ouweland · Jan G. M. Klijn · \\ Stephen P. Ethier · Mieke Schutte
}

Received: 8 February 2008/Accepted: 8 February 2008/Published online: 24 February 2008

(C) Springer Science+Business Media, LLC. 2008

\begin{abstract}
The CHEK2 protein plays a major role in the regulation of DNA damage response pathways. Mutations in the CHEK2 gene, in particular 1100delC, have been associated with increased cancer risks, but the precise function of $C H E K 2$ mutations in carcinogenesis is not known. Human cancer cell lines with CHEK2 mutations are therefore of main interest. Here, we have sequenced 38 breast cancer cell lines for mutations in the CHEK2 gene and identified two cell lines with deleterious CHEK2 mutations. Cell line UACC812 has a nonsense truncating mutation in the CHEK2 kinase domain (L303X) and cell line SUM102PT has the well-known oncogenic CHEK2 $1100 \mathrm{delC}$ founder mutation. Immunohistochemical analysis revealed that the two CHEK2 mutant cell lines expressed neither CHEK2 nor P-Thr ${ }^{68}$ CHEK2 proteins, implying abrogation of normal CHEK2 DNA repair functions. Cell lines UACC812 and SUM102PT thus are the first human CHEK2 null cell lines reported and should
\end{abstract}

M. Wasielewski · P. Hanifi-Moghaddam · A. Hollestelle .

J. G. M. Klijn · M. Schutte ( $\triangle)$

Department of Medical Oncology, Josephine Nefkens Institute,

Erasmus University Medical Center, PO Box 2040,

3000 CA Rotterdam, The Netherlands

e-mail: a.schutte@erasmusmc.nl

S. D. Merajver

Department of Internal Medicine, University of Michigan

Cancer Center, Ann Arbor, MI, USA

A. van den Ouweland

Department of Clinical Genetics, Erasmus University Medical

Center, Rotterdam, The Netherlands

S. P. Ethier

Barbara Ann Karmanos Cancer Institute, Detroit, MI, USA therefore be a major help in further unraveling the function of $C H E K 2$ mutations in carcinogenesis.

Keywords Cancer susceptibility - Cell lines .

Gene mutation $\cdot$ CHK2 $\cdot$ p53

\section{Introduction}

Cell cycle checkpoint kinase 2 (CHEK2, also known as CHK2, MIM604373) is a key regulator of DNA damage response pathways [1-3]. In response to DNA double strand breaks, CHEK2 is activated through ATM-mediated phosphorylations in the $\mathrm{N}$-terminal regulatory domain, specifically at residue $\mathrm{Thr}^{68}$. CHEK2 kinase is then fully activated by homodimerisation, intermolecular phosphorylation and subsequent release of active CHEK2 monomers. Activated CHEK2 kinase may control cell cycle arrest through phosphorylation of its substrates CDC25A and CDC25C, promote DNA repair through phosphorylation of BRCA1 and/or regulate apoptosis through phosphorylation of p53 [1, 2].

We and others identified the protein truncating CHEK2 1100delC mutation as a low-risk breast cancer susceptibility allele [4-6]. We recently have shown that CHEK2 $1100 d e l C$ also is a colorectal cancer susceptibility allele (MW and MS, manuscript submitted for publication). Although classified as a low-risk cancer allele, the CHEK2 1100delC mutation tends to be more prevalent in families with a high-risk cancer inheritance pattern. In addition, the CHEK2 1100delC mutation only partially segregates with the cancer phenotype in these families. Together, these observations have suggested a synergistic model in which the CHEK2 1100delC mutation acts in concert with another as-yet-unknown cancer susceptibility allele to confer high 
cancer risks [4-6]. Apart from the CHEK2 1100delC mutation, four other allelic variants have convincingly been associated with cancer risks: the non-synonymous I157T and S428F mutations, the IVS2+1G $>$ A splice site mutation and the truncating del5395 mutation [6]. Such a limited CHEK2 mutation profile renders the gene particularly amenable for a polygenic cancer susceptibility model that involves biological synergy among partners. However, thorough investigation of the biological mechanism of CHEK2-related carcinogenesis is hampered by the lack of human cancer cell lines with proven oncogenic CHEK2 mutations. Here, we report two novel deleterious CHEK2 mutant cell lines that were identified through an extensive CHEK2 mutation analysis of 38 human breast cancer cell lines.

\section{Materials and methods}

Breast cancer and colon cancer cell lines

The 38 human breast cancer cell lines used in this study are listed in Table 1 and have been described previously by Wasielewski et al. [7]. The SUM102PT cell line is generated in the Ethier laboratory (available at www.asterand.com) and the UACC 812 cell line is obtained from American Type Culture Collection (available at www.lgcpromochem-atcc. com). The twelve evaluated human colon cancer cell lines included Caco-2, COLO205, DLD-1, HCT15, HCT116, HT29, NCI-H716, RKO, SW403, SW480, SW620 and SW1116. All colon cancer cell lines were obtained from American Type Culture Collection. Cell lines DLD-1 and HCT15 were independently established from the same tumor [8].

Breast cancer families and control population

The CHEK2 L303X mutation was screened in bloodderived DNA from the youngest diagnosed breast cancer case of 290 breast cancer families from the southwestern Netherlands. All families had at least two breast cancer cases in first or second-degree relatives of whom at least one was diagnosed before age 60 years. Breast cancer families were ascertained through the Rotterdam Family Cancer Clinic at Erasmus MC. The 171 control cases were spouses of heterozygous cystic fibrosis mutation carriers ascertained through the department of Clinical Genetics at Erasmus MC. DNA of 69 European American and African American control cases were from the Coriell Human Variation Collection and were a kind gift by Dr. André G. Uitterlinden. All breast cancer cases gave informed consent
Table 1 CHEK2 mutation analysis of 38 human breast cancer cell lines

\begin{tabular}{|c|c|c|c|}
\hline $\begin{array}{l}\text { Breast cancer } \\
\text { cell lines } \\
\mathrm{N}=38\end{array}$ & $\begin{array}{l}C H E K 2 \\
\text { Variant }^{\mathrm{a}}\end{array}$ & $\begin{array}{l}\text { CHEK2 } \\
\text { protein } \\
\text { expression }\end{array}$ & $\begin{array}{l}\text { CHEK2 } \mathrm{Thr}^{68} \\
\text { protein } \\
\text { expression }\end{array}$ \\
\hline BT20 & wt & +++ & +++ \\
\hline BT483 & 2,7 & +++ & +++ \\
\hline BT549 & 7 & +++ & +++ \\
\hline CAMA-1 & 7 & ++ & ++ \\
\hline DU4475 & 2,7 & $+1-$ & ++ \\
\hline EVSA-T & 2,7 & +++ & +++ \\
\hline HCC1937 & wt & +++ & +++ \\
\hline Hs578T & 7 & +++ & +++ \\
\hline MCF-7 & 7 & +++ & +++ \\
\hline MDA-MD-134VI & 2,7 & + & ++ \\
\hline MDA-MD-157 & 7 & +++ & ++ \\
\hline $\begin{array}{c}\text { MDA-MD- } \\
175 \mathrm{VII}\end{array}$ & 7 & +++ & +++ \\
\hline MDA-MD-231 & 7 & $+1-$ & $+/-$ \\
\hline MDA-MD-330 & 1,7 & $+l-$ & $+/-$ \\
\hline MDA-MD-361 & 7 & ++ & ++ \\
\hline MDA-MD-415 & 7 & +++ & +++ \\
\hline MDA-MD-435S & 7 & ++ & ++ \\
\hline MDA-MD-436 & 7 & +++ & +++ \\
\hline MDA-MD-453 & 7 & ++ & ++ \\
\hline MDA-MD-468 & 7 & + & + \\
\hline MPE600 & 7 & + & + \\
\hline OCUB-M & 2,7 & n.d. & +++ \\
\hline SK-BR-3 & 7 & $+l-$ & ++ \\
\hline SK-BR-5 & wt & $+l-$ & + \\
\hline SK-BR-7 & 7 & +++ & ++ \\
\hline SUM52PE & 7 & +++ & +++ \\
\hline SUM102PT & $2,6,7$ & - & - \\
\hline SUM149PT & $1,4,7,8$ & $+1-$ & + \\
\hline SUM159PT & 7 & +++ & +++ \\
\hline SUM185PE & 2,7 & +++ & ++ \\
\hline SUM190PT & 2,7 & +++ & +++ \\
\hline SUM225CWN & 7 & +++ & ++ \\
\hline SUM229PE & 7 & + & + \\
\hline SUM1315M02 & 7 & +++ & ++ \\
\hline T47D & 2,7 & +++ & +++ \\
\hline UACC-812 & 3,5 & - & - \\
\hline UACC-893 & 7 & +++ & +++ \\
\hline ZR75-1 & 3 & +++ & +++ \\
\hline
\end{tabular}

${ }^{a}$ Identified CHEK2 gene variants are detailed in Table 2; n.d., not determined; +++ , nuclear staining in $>75 \%$ of cells; ++ , nuclear staining in $50-75 \%$ of cells; + , nuclear staining in $25-50 \%$ of cells; $+/-$, nuclear staining in $<25 \%$ of cells; - , no nuclear staining detected

Cell lines and variants in bold indicate deleterious mutants 
to screen for susceptibility genes, and the medical ethical committee of Erasmus MC approved this study.

\section{CHEK2 mutation analysis}

The complete coding sequence, including intron/exon boundaries, of CHEK2 (ENSG00000183765) was analyzed for genetic alterations. Exons 1 through 8 were amplified from genomic DNA by standard PCR [7]. Amplification of exons 9 through 14 was performed by long-range PCR and the $\sim 9.2 \mathrm{~kb}$ product served as template for nested PCR's for each of exons 9 through 14. CHEK2 amplification products were sequenced using BigDye ${ }^{\mathrm{TM}}$ Terminator v3.0 Cycle Sequencing mix (Applied Biosystems) and were analyzed on an ABI 3100 capillary sequencer. Unique sequence alterations were confirmed at least once on an independently generated (long-range) PCR product. Primer sequences and reaction conditions are available upon request.

\section{Azacytidine treatment}

Promoter hypermethylation was evaluated by treating exponentially growing cells with the demethylating agent 5-aza-2'-deoxycytidine (Sigma). Cells were cultured for 3 days with daily addition of $10 \mu \mathrm{M}$ azacytidine. RNA of azacytidine-treated cells was isolated at the fourth day using RNeasy kit (Qiagen). CHEK2 transcript expression was determined by RT-PCR, using Qiagen OneStep RT-PCR kit and $C H E K 2$-specific primers annealing to sequences in exon 1 and exons 10-11.

\section{CHEK2 immunohistochemistry}

A cell line tissue microarray (TMA) was constructed by arraying triplicate 1-mm punches of paraffin embedded cell lines in a recipient paraffin wax block, using an automatic tissue micoarray system (Beecher). Normal placenta, colon and kidney tissues were arrayed as controls. Paraffin sections $(4-\mu \mathrm{m})$ of the cell line TMA were mounted on starfrost glass slides (Knittel Gläser), deparaffinized and dehydrated. Epitopes were retrieved in $0.1 \mathrm{M}$ Tris-EDTA pH 9.0 for $30 \mathrm{~min}$ at $100^{\circ} \mathrm{C}$ in a microwave oven and slides were blocked with 2\% BSA in PBS for 30 min at RT. CHEK2 staining was performed for $1 \mathrm{~h}$ at RT with mouse monoclonal antibody NCL-CHK2 (clone DCS 270.1, 1:40; Novocastra Laboratories). Staining of phosphorylated CHEK2 at residue $\mathrm{Thr}^{68}$ was done overnight at $4{ }^{\circ} \mathrm{C}$ with rabbit polyclonal antibody CHK2 phosphoT68 (clone E126, 1:100; Abcam). Isotype-matched mouse monoclonal antibody X0943 (1:40; Dako) and normal rabbit IgG sc-2027 (1:1000; Santa Cruz Biotechnology) were used as negative controls. Positive control antibodies were Vimentin for
SUM102PT (clone V9, 1:4500; Dako) and Cytokeratin 8/18 for UACC812 (clone NCL5D3, 1:50; Biogene). Reactions were visualized using the EnVision $+{ }^{\circledR}$ System-HRP (DAB) kit (DakoCytomation) as described [9].

\section{Results and discussion}

CHEK2 mutation analysis in human breast cancer cell lines identifies two deleterious mutants

Sequencing of the CHEK2 gene identified eight unique sequence alterations among 38 breast cancer cell lines (Tables 1 and 2). Six known single nucleotide polymorphisms included five intronic and one synonymous (E84E) sequence alterations that together were identified 48 times, varying from once to 33 times. The two non-synonymous sequence alterations c.908T $>$ A and c.1100delC were each identified once.

The hemizygous CHEK2 c.908T $>$ A mutation was identified in cell line UACC812, predicting the substitution of a leucine to a termination codon at amino acid position 303 that is located in the kinase domain of the CHEK2 protein (p.L303X; Tables 1, 2). The patient from whom UACC812 was derived was first diagnosed with breast carcinoma at age 39 years [10]. The original tumor or blood-derived DNA were however unavailable for analysis, precluding confirmation of the mutation. Although the cancer history of the family was not known and CHEK2 L303X has never been reported, the early age at diagnosis might be suggestive for a germ line mutation. We therefore genotyped the L303X mutation in 290 Dutch familial breast cancer cases and in 171 geographically-matched controls, but no positive cases were identified. As CHEK2 L303X was identified in a cell line of American origin, we also screened 69 European American and African American controls for the mutation, but again none were positive. Together, these results suggest that the L303X mutation is not a common variant among Dutch and American populations. It also is possible that the mutation has been acquired during in vitro propagation of UACC 812 cells. Be what it may, the homozygous deleterious nature of the L303X mutation renders the UACC812 cell line the first human CHEK2 null cell line.

The heterozygous CHEK2 c.1100delC mutation was identified in cell line SUM102PT, predicting a shift in the CHEK2 reading frame with an insertion of 14 new amino acids after codon 367 followed by a termination codon (p.T367fsX15; Tables 1, 2). Cell line SUM102PT was established from a patient who was diagnosed with in situ ductal breast carcinoma at age 56 years [11]. The family of the patient had a hereditary cancer inheritance pattern, but no details are known. Analysis of blood-derived DNA from 
Table 2 CHEK2 sequence variants identified among 38 human breast cancer cell lines

\begin{tabular}{|c|c|c|c|c|c|}
\hline CHEK2 variant & Location & Nucleotide change $^{\mathrm{a}}$ & Predicted protein change ${ }^{\mathrm{b}}$ & Type of variant ${ }^{c}$ & Number of cell lines \\
\hline 1 & Exon 1 & c. $252 \mathrm{~A}>\mathrm{G}$ & p.E84E & SNP (rs1805129) & 2 \\
\hline 2 & Intron 1 & c. $319+38$ insA & - & SNP (rs3841692) & 9 \\
\hline 3 & Intron 5 & c. $793-127 \mathrm{~T}>\mathrm{C}$ & - & SNP (rs9625541) & 2 \\
\hline 4 & Intron 5 & c. $793-11 \mathrm{G}>\mathrm{A}$ & - & SNP (rs5997387) & 1 \\
\hline 5 & Exon 7 & c. $908 \mathrm{~T}>\mathrm{A}$ & p.L303X & Oncogenic & 1 \\
\hline 6 & Exon 10 & c.1100delC & p.T367fsX15 & Oncogenic & 1 \\
\hline 7 & Intron 11 & c. $1375+78 \mathrm{C}>\mathrm{G}$ & - & SNP (rs5762749) & 33 \\
\hline 8 & Intron 13 & c. $1542+11 \mathrm{~T}>\mathrm{A}$ & - & SNP (rs17881716) & 1 \\
\hline
\end{tabular}

${ }^{a}$ Numbering of nucleotide changes according CHEK2 ensemble gene ID ENSG00000183765

${ }^{\mathrm{b}}$ Frame shift mutation is indicated by the first changed codon and the number of newly encoded codons, including premature termination codon $\mathrm{X}$

c Oncogenic; variant associated with cancer susceptibility [3] or presumed oncogenic as it predicts a premature termination codon (L303X). Both CHEK2 mutant cell lines did not express CHEK2 and P-Thr ${ }^{68}$ CHEK2 proteins

the SUM102PT patient confirmed that the CHEK2 1100delC mutation was present in her germ line. The CHEK2 1100delC mutation is indeed a well-known oncogenic founder mutation that has been associated with an increased breast cancer risk [4-6]. Thus, the SUM102PT cell line is the first oncogenic CHEK2 cell line reported thus far.

The two deleterious CHEK2 mutant cell lines do not express CHEK2 and P-Thr ${ }^{68}$ CHEK2 proteins

To address biological consequences of the identified mutations, we analyzed the 38 breast cancer cell lines as well as the CHEK2 mutant colorectal cancer cell line HCT15 for CHEK2 and P-Thr ${ }^{68}$ CHEK2 protein expression by immunohistochemistry (Table 1, Fig. 1, [12, 13]). All 36 CHEK2 wild-type breast cancer cell lines showed CHEK2 and P-Thr ${ }^{68}$ CHEK2 protein expression, where the level of CHEK2 protein expression generally was in concordance with the expression level of P-Thr ${ }^{68}$ CHEK2. Cell line HCT15 had weak CHEK2 and P-Thr ${ }^{68}$ CHEK2 protein expression, consistent with its reported impaired CHEK2 function due to bi-allelic CHEK2 missense mutations (Fig. 1, Table 4, [12, 13]). In contrast, neither CHEK2 nor $\mathrm{P}^{-\mathrm{Thr}^{68}}$ CHEK2 protein expression was detected in the CHEK2 mutant cell lines SUM102PT and UACC812 (Fig. 1), implying complete loss of CHEK2 function in these cell lines.

No CHEK2 promoter hypermethylation in SUM102PT cells

Absence of CHEK2 and P-Thr ${ }^{68}$ CHEK2 protein expression in cell line SUM102PT was somewhat unexpected as this cell line had retained a $C H E K 2$ wild-type allele. To exclude
CHEK2 promoter hypermethylation as an additional mechanism for $C H E K 2$ inactivation in cell line SUM102PT, we treated SUM102PT cells with the demethylating agent azacytidine. Treatment with azacytidine did however not upregulate CHEK2 transcript levels in SUM102PT cells, suggesting that $C H E K 2$ promoter hypermethylation is not underlying its decreased transcript expression and absent protein expression in cell line SUM102PT.

CHEK2 and $p 53$ mutations are mutually exclusive in human cancer cell lines

It is well established that CHEK2 is an upstream activator of $\mathrm{p} 53$ proteins but it is as yet unclear whether both proteins also function in the same tumor suppressor pathway $[1,2]$. Such functional interaction predicts that $C H E K 2$ and p53 mutations occur mutually exclusively in a single tumor. We have evaluated the CHEK2 and $p 53$ mutation status in a cohort of 54 human cancer cell lines. This cohort included the here described 38 breast cancer cell lines [7], five previously reported prostate cancer cell lines [14] and 11 unique colon cancer cell lines with known $p 53$ mutation status [15-17] that we also have analyzed for CHEK2 mutations (Table 3). Forty-two cell lines were p53 mutant and five cell lines were CHEK2 mutant. The five CHEK2 mutant cell lines included the here reported SUM102PT and UACC 812 breast cancer cell lines, the colorectal cancer cell lines HCT15 and HCT116 and the prostate cancer cell line LNCaP (Table 4). Cell line HCT15 has biallelic inactivation of the CHEK2 gene as it has the R145W mutation in the fork head-associated domain of CHEK2 and the A247D mutation in the kinase domain $[12,13]$. Cell lines HCT116 and LNCaP carry the heterozygous missense mutations $\mathrm{L} 355 \mathrm{P}$ and $\mathrm{T} 387 \mathrm{~N}$ in the CHEK2 kinase domain, respectively [14, 18]. The CHEK2 R145W 


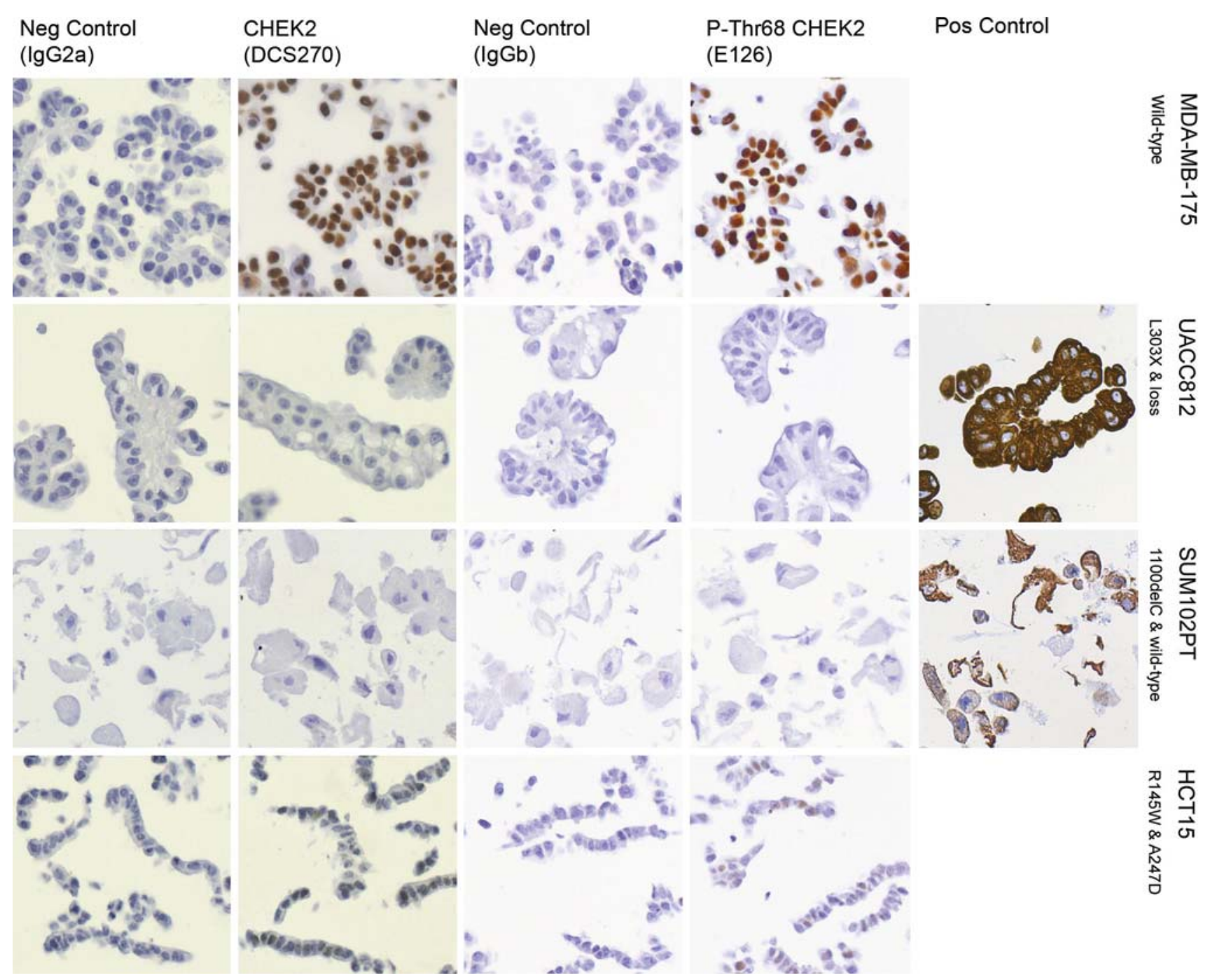

Fig. 1 Absence of CHEK2 protein expression in mutant CHEK2 breast cancer cell lines. CHEK2 mutant breast cancer cell lines UACC812 and SUM102PT do not express CHEK2 or P-Thr ${ }^{68}$ CHEK2 protein, in contrast to CHEK2 wild-type cell line MDA-MB175. CHEK2 mutant colorectal cancer cell line HCT15 shows weak
CHEK2 and P-Thr ${ }^{68}$ CHEK2 protein expression. Negative control antibodies were isotype-matched for CHEK2 and P-Thr ${ }^{68}$ CHEK2 antibodies. Positive control antibodies were Vimentin for SUM102PT and Cytokeratin 8/18 for UACC812

is likely oncogenic as this residue is crucial for interaction of wild-type p53 proteins with DNA [15, 20]. Cell line HCT15 also was reported to have the $p 53$ P153A missense mutation [17]. Yet, this mutation could not be confirmed by us nor by others that had sequenced the $p 53$ gene in HCT15 and/or DLD1 [15]. Thus, only one of the 54 human cancer cell lines (HCT15) had oncogenic mutations in both CHEK2 and p53 $(P=0.005$ using Fisher's Exact Test, Table 4), suggesting that coincident CHEK2 and $p 53$ mutant cells do not have a selective survival advantage compared to either CHEK2 or p53 mutant cells. Our observation is in concordance with a report on 84 primary prostate cancers that had been screened for mutations in the CHEK2 and $p 53$ genes [14]. Those results had not been significant because too few mutant tumors had been 
Table 3 Mutual exclusiveness of $C H E K 2$ and $p 53$ mutations among 54 human cancer cell lines (CHEK2 and p53 mutational status was determined in 54 breast, colorectal and prostate cancer cell lines. Note that only one of 54 cell lines is $C H E K 2$ and $p 53$ mutant $(P=0.005))$

\begin{tabular}{lcccc}
\hline CHEK2 and $p 53$ oncogenic mutations & \multicolumn{2}{l}{ Human cancer cell lines } & Total \\
\cline { 2 - 5 } & Breast cancer & Colorectal cancer & Prostate cancer \\
\hline CHEK2 wild-type and $p 53$ wild-type & 6 & 1 & 0 & 7 \\
CHEK2 wild-type and $p 53$ mutant & 30 & 8 & 4 & 42 \\
CHEK2 mutant and $p 53$ wild-type & 2 & 1 & 1 & 4 \\
CHEK2 mutant and $p 53$ mutant & 0 & 11 & 5 & 54 \\
Total & 38 & & 5 \\
\hline
\end{tabular}

p53 sequence variant reported in Ref. 15

Table 4 Mutual exclusiveness of $C H E K 2$ and $p 53$ mutations among 54 human cancer cell lines (Overview of identified CHEK2 variants in human cancer cell lines)

\begin{tabular}{lll}
\hline Cell line & CHEK2 mutation & p53 mutation \\
\hline Breast cancer & & \\
SUM102PT & T367fsX15 & wild-type \\
UACC812 & L303X & wild-type \\
Colorectal cancer & & \\
HCT15/DLD-1 & A247D, R145W & S241F \\
HCT116 & L335P & wild-type \\
Prostate cancer & & \\
LNCaP & T387N & wild-type \\
\hline
\end{tabular}

p53 sequence variant reported in Ref. 15

identified (11 CHEK2 mutant and 11 p53 mutant; $P=0.8$ ). However, combining both datasets conclusively shows that mutations in the CHEK2 and p53 genes are mutually exclusive $(P=0.02)$. Our analysis thus implies that CHEK2 and p53 proteins indeed operate in the same tumor suppressor pathway and that a main oncogenic function of CHEK2 involves p53 mediated G1 cell cycle arrest.

In conclusion, we here report two breast cancer cell lines with deleterious CHEK2 mutations, L303X and 1100delC. Both mutations generate a premature termination codon in the encoded CHEK2 transcripts leading to loss of CHEK2 and $\mathrm{P}-\mathrm{Thr}^{68}$ CHEK2 protein expression. These mutation data, together with our previous mutation reports of the BRCA1, E-cadherin, p53, PIK3CA, PTEN and RAS genes, provide a mutation profile of human breast cancer cell lines that will be a useful tool in functional and in vitro breast cancer studies [7, 9, 21, 22].

Acknowledgement Funding was provided by the Dutch Cancer Society, grant DDHK 2003-2862

\section{References}

1. Bartek J, Lukas J (2003) Chk1 and Chk2 kinases in checkpoint control and cancer. Cancer Cell 3:421-429
2. Ahn J, Urist M, Prives C (2004) The Chk2 protein kinase. DNA Repair (Amst) 3:1039-1047

3. Zhou BB, Elledge SJ (2000) The DNA damage response: putting checkpoints in perspective. Nature 408:433-439

4. Meijers-Heijboer H, van den Ouweland A, Klijn J et al (2002) Low-penetrance susceptibility to breast cancer due to CHEK2(*)1100delC in noncarriers of BRCA1 or BRCA2 mutations. Nat Genet 31:55-59

5. Vahteristo P, Bartkova J, Eerola $\mathrm{H}$ et al (2002) A CHEK2 genetic variant contributing to a substantial fraction of familial breast cancer. Am J Hum Genet 71:432-438

6. Nevanlinna H, Bartek $\mathbf{J}$ (2006) The CHEK2 gene and inherited breast cancer susceptibility. Oncogene 25:5912-5919

7. Wasielewski M, Elstrodt F, Klijn JG, Berns EM, Schutte M (2006) Thirteen new p53 gene mutants identified among 41 human breast cancer cell lines. Breast Cancer Res Treat 99: 97-101

8. Chen TR, Dorotinsky CS, McGuire LJ, Macy ML, Hay RJ (1995) DLD-1 and HCT-15 cell lines derived separately from colorectal carcinomas have totally different chromosome changes but the same genetic origin. Cancer Genet Cytogenet 81:103-108

9. Elstrodt F, Hollestelle A, Nagel JH et al (2006) BRCA1 mutation analysis of 41 human breast cancer cell lines reveals three new deleterious mutants. Cancer Res 66:41-45

10. Meltzer P, Leibovitz A, Dalton W et al (1991) Establishment of two new cell lines derived from human breast carcinomas with HER-2/neu amplification. Br J Cancer 63:727-735

11. Sartor CI, Dziubinski ML, Yu CL, Jove R, Ethier SP (1997) Role of epidermal growth factor receptor and STAT-3 activation in autonomous proliferation of SUM-102PT human breast cancer cells. Cancer Res 57:978-987

12. Bell DW, Varley JM, Szydlo TE et al (1999) Heterozygous germ line hCHK2 mutations in Li-Fraumeni syndrome. Science 286:2528-2531

13. Lee SB, Kim SH, Bell DW et al (2001) Destabilization of CHK2 by a missense mutation associated with Li-Fraumeni Syndrome. Cancer Res 61:8062-8067

14. Zheng L, Wang F, Qian C et al (2006) Unique substitution of CHEK2 and TP53 mutations implicated in primary prostate tumors and cancer cell lines. Hum Mutat 27:1062-1063

15. Petitjean A, Mathe E, Kato $S$ et al (2007) Impact of mutant p53 functional properties on TP53 mutation patterns and tumor phenotype: lessons from recent developments in the IARC TP53 database. Database version R12 November 2007. Hum Mutat 28:622-629

16. Eshleman JR, Casey G, Kochera ME et al (1998) Chromosome number and structure both are markedly stable in RER colorectal cancers and are not destabilized by mutation of p53. Oncogene 17:719-725 
17. O’Connor PM, Jackman J, Bae I et al (1997) Characterization of the p53 tumor suppressor pathway in cell lines of the National Cancer Institute anticancer drug screen and correlations with the growth-inhibitory potency of 123 anticancer agents. Cancer Res 57:4285-4300

18. Williams LH, Choong D, Johnson SA, Campbell IG (2006) Genetic and epigenetic analysis of CHEK2 in sporadic breast, colon, and ovarian cancers. Clin Cancer Res 12:6967-6972

19. Schutte M, Seal S, Barfoot R et al (2003) Variants in CHEK2 other than 1100delC do not make a major contribution to breast cancer susceptibility. Am J Hum Genet 72:1023-1028
20. Cho Y, Gorina S, Jeffrey PD, Pavletich NP (1994) Crystal structure of a p53 tumor suppressor-DNA complex: understanding tumorigenic mutations. Science 265:346-355

21. Hollestelle A, Elstrodt F, Nagel JH, Kallemeijn WW, Schutte M (2007) Phosphatidylinositol-3-OH kinase or RAS pathway mutations in human breast cancer cell lines. Mol Cancer Res 5:195-201

22. van de Wetering M, Barker N, Harkes IC et al (2001) Mutant E-cadherin breast cancer cells do not display constitutive Wnt signaling. Cancer Res 61:278-284 